\title{
Research on the Learning Motivation of College Students in the Online Teaching
}

\author{
Ting Sun ${ }^{1, *}$, Xue $\operatorname{Sun}^{2}$ \\ ${ }^{1}$ School of Public Finance and Administration, Harbin University of Commerce, Harbin, Heilongjiang 150028, China \\ ${ }^{2}$ School of Public Finance and Administration, Harbin University of commerce, Harbin, Heilongjiang 150028, China \\ *Corresponding author. Email: 790231496@qq.com
}

\begin{abstract}
Against the backdrop of advanced network technology, the learning styles and approaches of college students have been developing in a progressive manner, and the online teaching in particular has grown into a new norm. In the process of online teaching, college students' lack of planning, supervision and interaction leads to their insufficient learning motivation and poor learning effect. Therefore, this paper analyzes the online teaching on college students' learning motivation on the basis of elaborating the content of the online environment, and proposes strategies to strengthen the cultivation of college students' learning motivation.
\end{abstract}

Keywords: college students, online teaching, learning motivation.

\section{INTRODUCTION}

\subsection{Definition of Concepts}

Online environment refers to the scope or space centered on multimedia technology and computer network [1]. Online teaching is a structural form of stable relationship and activity process between teachers and students, while network is used as teaching support. In particular, constructivism learning theory, which advocates learner-centered learning under the guidance of the teacher, is considered to be the most suitable model for the application of online teaching[2].

\subsection{Features of Online Teaching}

\subsubsection{Convenient Online Teaching}

Online teaching proves to be convenient for teachers and students. Compared with the fixed location and schedule of learning in offline teaching, online teaching is less restricted by environmental factors. As the subject of learning, students can not only design and arrange the learning plan according to their own conditions, but also make full use of the fragmented time for learning.

\subsubsection{Reduction of Teaching Costs}

The two most common teaching methods used in online learning are live lessons and pre-recorded lessons.
Teachers are allowed to record their lectures simultaneously through the online teaching platform in the process of live lessons. The pre-recorded lessons facilitate college students' further learning after class, and reduce the teaching costs of teachers.

\subsubsection{Diversified Teaching Organization Modes}

Compared with the traditional system of "giving lectures in the classroom", online teaching modes are diversified, including MOOC, Microlecture, Flipped Classroom, etc. It breaks the single group teaching organization mode, and thus improves the learning atmosphere while facilitating students to enter the learning state more efficiently.

\subsubsection{Balanced Distribution of Educational Resources}

The main contradiction in education lies in the unbalanced distribution of educational resources. The differences between urban and rural areas, between the east and west, and between different regions in the city make it impossible to equalize educational resources. Online teaching can help alleviate most of the problems of uneven educational resources and provide students with a more equitable opportunity to receive education. 


\section{THE INFLUENCE OF ONLINE ENVIRONMENT ON COLLEGE STUDENTS' LEARNING MOTIVATION}

With the rapid popularization of information technology and the progressive development of educational ideas, online education has emerged as a new trend of modern education. The teaching in an online environment facilitates the teaching activities among teachers and students and improves students' learning effect; however, it is also prone to weaken college students' learning motivation.

\subsection{Insufficient Learning Plan and Motivation}

One of the core ideas in educational psychology is that many students' lacking the insufficient learning motivation rests with their failure in establishing a connection between their present efforts and their future life. Only when a college student clearly understands the benefits of the course he or she is taking can the student be motivated to learn. But the case is that, some college students' completion of online courses is for the only purpose of getting credits for their degrees, and the attendance in elective courses is to cope with their teachers or to ensure their grades. Hardly do they consider whether taking these online courses will help them in their future studies or career. Students, who lack interest in the lessons and have no plans for their life goals, have thus weak learning motivation, resulting in their weak learning efficiency and poor leaning quality.

\subsection{Poor Learning Self-discipline in the Absence of Supervision}

On account of the rapid development of the network information all over the society and the widespread application of electronic devices, some problems in relation to colleges students also come into being such as learners' excessive reliance on or addiction to virtual networks, reluctance to communicate and interact with learning partners face-to-face, and lack of contact with the person in reality in the process of online learning [3]. Students who have just entered university still have a strong dependence on teachers due to a long period of traditional classroom education in the past. Unlike high school and junior high school students, who are supervised by teachers and parents, college students are completely dependent on their own self-discipline. Therefore, in the absence of direct supervision from teachers and parents, along with little self-discipline, students are easily distracted by irrelevant information on the Internet and unable to concentrate on systematic and in-depth learning, resulting in poor academic performance.

\subsection{Deficient Interaction Leading to Poor Learning Results}

One of the deficiencies of online education is "interactivity" [4]. Although online education breaks the boundaries of time and space, the separation of locations is not conducive to the emotional development between teachers and students, weakening the role of emotional factors, verbal communication and body language in teaching. Some good teachers will infect students with their unique ways and persona to create students' strong interest in learning, which, however, are difficult to achieve on online classes. The lack of real-time interactive feedback between teachers and students can make it difficult for teachers to grasp the progress of course, leading to the result of spoon-feeding education. In addition, some teachers only upload video learning courseware before class for students' self-learning. The deficiency in interaction and feedback for students in the learning process naturally leads to the students' distraction and no interest in online learning.

\subsection{Redundant Network Information Engendering Low Learning Efficiency}

Due to the great openness and interactivity of online teaching resources, college students are prone to getting lost in the network if without effective guidance. Firstly, the socialization of education supply has led to the exponential growth of educational information on the Internet, and it is a headache for students to find the suitable and effective information among the miscellaneous information. Secondly, there are a lot of resources that are not related to learning in the online environment. The push information that are constantly jumping on the page are far more tempting than online lectures to learners, who will easily slack off in their studies. In addition, owing to the feature of strong circulation of information on the Internet, the same and similar online teaching videos are easy to spread, and there is a risk that the videos will be "taken out of context" when they flow out of the network. Besides, it is often difficult for the Internet users to distinguish the true from the false, which easily leads to the fermentation of public opinion and affects the learning mentality of college students.

\section{STRATEGIES TO REINFORCE COLLEGE STUDENTS' LEARNING MOTIVATION}

\subsection{Stimulating Students' Interest in Learning Through Smart Classrooms}

Referring to Keller's ARCS motivation model, arousing students' attention and interest will stimulate 
students' learning motivation. If students' learning interest is high, their learning motivation is high, and vice versa. Therefore, the key to improving students' learning motivation is to stimulate students' interest in learning. Intelligent platforms are expected be used in colleges and universities to establish more smart classrooms, while building democratic, equal and cooperative teacher-student relationships, so as to realize that students can choose courses independently across majors and universities according to their personal interests and future career plans. Students will no longer learn to cope with exams, but to choose courses according to their own interests, thus achieving the purpose of student-oriented education while improving teaching quality.

\subsection{Strengthening Students' Self-control through Individualized Teaching}

The miscellaneous information on the Internet leads to the inevitable temptation and pressure for students to learn in an online environment. Students with strong self-control ability, who make good study plans without distractions, will learn well and their motivation will be significantly improved. Students with poor self-control ability and thus without clear learning plans and goals, however, are prone to do things unrelated to learning on the Internet during learning time. Their uncertain motivation will not give rise to expected learning results. Therefore, when teaching in an online environment, educators should fully consider the different conditions of college students, make individualized learning goals and plans according to students' own traits. Teachers will help students improve their self-control ability, guide them to maintain good learning motivation in the online environment and thus improve students' learning effect.

\subsection{Improving Teachers' Information Literacy Through Correct Guidance}

Online teaching holds teaching concepts different from traditional teaching. While improving online teaching skills, teachers should abandon the shackles of traditional education and establish a scientific and reasonable teaching concept[5]. Students' learning avenues are exploding in the context of the online education environment, so teachers should keep up with the times, not only with excellent professional and teaching abilities, but also with the ability to master the use of online education resources. Teachers are expected to keep learning to grasp basic teaching skills. Secondly, teachers should be proficient in using online teaching software to present diversified teaching contents for students through live streaming, video, graphics, face-to-face teaching, exam assessment and real-time interaction to meet different students' learning preferences, while focusing students' concentration with novel learning methods.

\subsection{Applying Online Learning Resources Rationally through Resource Integration}

In the process of online teaching, visualized online educational resources will increase students' attention and learning interest, thus increasing their learning motivation. Therefore, educators should use learning resources flexibly and take the initiative to create courses and courseware of interest to students in order to increase their learning motivation. Besides, in order to enhance students' learning effect, teaching resources will be designed with personalized and attractive features that correspond to students' actual level. The richer the type of resources, the more obvious students' learning interest and effect will be. Once the teaching resources are detached from the actual learning conditions of students, the students' motivation and effectiveness will be affected. Therefore, when adopting online teaching, teaching resources are not the more the better, but educators should take the initiative to integrate and adapt teaching resources. The closer the adapted form is to life, the more attractive it is, and the more it can enhance students' initiative and learning motivation. In conclusion, educators should use online educational resources reasonably in the online teaching, help students learn effectively through different educational resources, and enhance students' learning interest and motivation.

\section{CONCLUSION}

With the development of information technology, modern education and teaching methods from single to multiple, online teaching has become an indispensable teaching method in Colleges, how to improve the learning motivation of college students has become a research hotspot. However, due to the new teaching method of online education, our understanding and research are not deep enough, and the teaching application is not effective enough, college students' learning motivation is affected in the process of online learning. Therefore, we need to take various measures to improve students' learning motivation from various aspects and angles, so as to promote the high-quality development of education.

\section{ACKNOWLEDGMENT}

Supported by Key Project of Heilongjiang Province Educational Science 14th Five-Year Plan 2020(No.GJB1421431).

\section{REFERENCES}

[1] $\mathrm{Xu}$ Haixia. Research on the current situation of college students' learning motivation and its influencing factors under the support of online 
environment[D]. Northwest Normal University, 2013.

[2] Gao Xiaohui, Zheng Hui. The construction of English phonetics teaching mode under the network multimedia environment $[\mathrm{J}]$. Continue Education Research, 2011(08):101-102.

[3] Zhang Haisheng, Fan Ying. New forms of learning in the era of "Internet + education": main types, common features and effective realization[J]. Distance Education in China, 2018(10):24-34.

[4] Ingerham,L. Interactivity in the Online Learning Environment: A Study of Users of the North Carolina Virtual Public School[J]. Quarterly Review of Distance Education, 2012(2) :65-75.

[5] Tian Aili. Role transformation and comprehensive quality improvement of teachers under flipped classroom teaching mode $[\mathrm{J}]$. Research on teacher education, 2015,27 (05): 84-88 